\title{
Phenolic compounds from the fungus Inonotus obliquus and their antioxidant properties
}

\author{
Byung Soon Hwang, In-Kyoung Lee and Bong-Sik Yun \\ The Journal of Antibiotics (2016) 69, 108-110; doi:10.1038/ja.2015.83; published online 29 July 2015
}

The medicinal fungus Inonotus obliquus (Pers.: Fr.) Pilat (family Hymenochaetaceae) is widely distributed in Europe, Asia and North America. ${ }^{1}$ This mushroom, which lives on tree trunks of Betula (birch) but rarely on Ulmus, Alnus and Fraxinus, has been used as a folk medicine for treating cancer in Russia and western Siberia, and has also been used to prevent and treat heart, liver and stomach diseases and tuberculosis. ${ }^{2,3}$ Chemical investigations show that I. obliquus produces a diverse range of secondary metabolites, including phenolic compounds, ${ }^{4}$ melanins ${ }^{5}$ and lanostane-type triterpenoids. ${ }^{6}$ Among these are active components with antioxidant, ${ }^{4}$ antitumor ${ }^{7}$ and antiviral activities, ${ }^{8}$ as well as compounds that improve human immunity against pathogenic microbial infections.

Reactive oxygen species are major primary catalysts for initiating oxidation in vivo and in vitro. Reactive oxygen species are associated with many diseases and degenerative processes that occur during aging. ${ }^{9-11}$ Accumulating excess reactive oxygen species damages lipids, proteins, carbohydrates and DNA, leading to oxidative stress, loss of cell function and apoptosis or necrosis. ${ }^{12,13}$ All of these biochemical processes are common in various diseases, such as cancers, inflammation, atherosclerosis and cardiovascular disease. ${ }^{14}$ Therefore, exploring the functions of antioxidants that scavenge reactive oxygen species may be of great value to prevent the onset and propagation of oxidative stress.

As part of our search for free radical scavengers from medicinal fungi, two new phenolic antioxidants 1 and 2 were isolated with known compounds 4-(3,4-dihydroxyphenyl)but-3-en-2-one (3), 4-hydroxy-3,5-dimethoxybenzoic acid (4), 3,4-dihydroxybenzaldehyde (5), 4-hydroxybenzene-1,3-dioic acid (6) and 3,4-dihydroxybenzoic acid (7) from a methanol extract of the I. obliquus fruiting body (Figure 1). In this study, we describe the isolation and structural determination of the phenolic antioxidants from the I. obliquus fruiting body as well as their antioxidant properties.

The I. obliquus fruiting bodies were purchased at an herbal drug market in Keumsan, Chungnam Province, Korea. The ground fruiting bodies $(5 \mathrm{~kg})$ were extracted twice with $70 \%$ aqueous methanol at $60{ }^{\circ} \mathrm{C}$ for $12 \mathrm{~h}$. After removing the methanol under reduced pressure, the aqueous solution was partitioned between hexane, chloroform, ethyl acetate, and butanol and water, in that order. Compound 1 was purified from the butanol-soluble portion, which was separated by silica gel column chromatography, and eluted with stepwise ethyl acetate: methanol (20:1-1:1, v/v). The phenolic fraction was chromatographed on a Sephadex LH-20 column (Pharmacia, Uppsala, Sweden) eluted with $20 \%$ aqueous methanol, followed by preparative HPLC (column: $\mathrm{C}_{18}$ Cosmosil i.d. $20 \times 150 \mathrm{~mm}$, solvent: a gradient of 20-90\% aqueous methanol $/ 0.04 \%$ trifluoroacetic acid, flow rate: $5 \mathrm{ml}$ per minute) to afford compound $\mathbf{1}(9.1 \mathrm{mg})$. The ethyl acetate-soluble fraction was subjected to Sephadex LH-20 column chromatography and eluted with $70 \%$ aqueous methanol to yield two fractions (Fr. 1 and Fr. 2). Fr. 1 was chromatographed on a Sephadex LH-20 column and eluted with methanol to give compound $7(6.8 \mathrm{mg})$. Compounds $5(12.1 \mathrm{mg})$ and $\mathbf{6}(15.2 \mathrm{mg})$ were purified by chromatography using an ODS-Sepak cartridge and eluted with a gradient of increasing methanol $(20-100 \%)$ in water, followed by preparative reverse-phase HPLC (column: $\mathrm{C}_{18}$ Cosmosil i.d. $20 \times 150 \mathrm{~mm}$, solvent: gradient of 20-90\% aqueous methanol $/ 0.04 \%$ trifluoroacetic acid, flow rate: $5 \mathrm{ml}$ per minute). Fr. 2 was purified by chromatography using an ODSSepak cartridge and eluted with a gradient of increasing methanol (20$100 \%$ ) in water to give two fractions (Fr. 2-a and Fr. 2-b). Compound $2(7.6 \mathrm{mg})$ was purified from Fr. 2-a by preparative reverse-phase HPLC and eluted with $30 \%$ aqueous methanol/0.04\% trifluoroacetic acid. Compounds $3(11.8 \mathrm{mg})$ and $4(10.1 \mathrm{mg})$ were isolated from fraction 2 -b by preparative reversed-phase HPLC $\left(\mathrm{C}_{18}\right.$ column, gradient of $25-90 \%$ aqueous methanol/0.04\% trifluoroacetic acid).

Compound 1 was obtained as a yellow powder, and its Electrospray ionization mass in positive mode provided a quasi-molecular ion peak at $m / z 251[\mathrm{M}+\mathrm{H}]^{+}$. The molecular formula of 1 was $\mathrm{C}_{11} \mathrm{H}_{6} \mathrm{O}_{7}$ based on the high resolution electron ionization mass $\left(\mathrm{m} / z 250.0110[\mathrm{M}]^{+}\right.$, calcd 250.0114) in combination with ${ }^{1} \mathrm{H}$ and ${ }^{13} \mathrm{C}$ nuclear NMR data (Table 1). The UV $\lambda_{\max }(\mathrm{MeOH})(\log \varepsilon)$ at 216 (4.26), 239 (3.91) and 285 (3.41) nm suggested that 1 was a coumarin derivative. The ${ }^{1} \mathrm{H}$ NMR spectrum in $\mathrm{CD}_{3} \mathrm{OD}$ showed three aromatic methine signals at $\delta$ $8.84(1 \mathrm{H}$, br. s), $8.06(1 \mathrm{H}, \mathrm{dd}, J=1.4,8.9 \mathrm{~Hz})$ and $7.80(1 \mathrm{H}, \mathrm{d}$, $J=8.9 \mathrm{~Hz}$ ). Eleven carbons in the ${ }^{13} \mathrm{C}$ NMR spectrum, including three carbonyl carbons at $\delta 167.1,165.7$ and 159.8; two oxygenated $\mathrm{sp}^{2}$

Division of Biotechnology and Advanced Institute of Environment and Bioscience, College of Environmental and Bioresource Sciences, Chonbuk National University, Iksan, Korea Correspondence: Professor B-S Yun, Division of Biotechnology and Advanced Institute of Environment and Bioscience, College of Environmental and Bioresource Sciences, Chonbuk National University, Gobong-ro 79, Iksan 570-752, Korea.

E-mail: bsyun@jbnu.ac.kr

Received 26 May 2015; revised 22 June 2015; accepted 29 June 2015; published online 29 July 2015 
<smiles>C#Cc1c(O)c(=O)oc2ccc(C(=O)O)cc12</smiles>

1<smiles>COc1cc(C(=O)O)cc(OC)c1O</smiles>

4<smiles>O=C(O)c1ccc(O)c(-c2cc(C(=O)O)ccc2O)c1</smiles>

2<smiles>CC(=O)/C=C/c1ccc(O)c(O)c1</smiles>

3<smiles>O=Cc1ccc(O)c(O)c1</smiles>

5<smiles>O=C(O)c1ccc(O)c(C(=O)O)c1</smiles>

6<smiles>O=C(O)c1ccc(O)c(O)c1</smiles>

7

Figure 1 Structures of compounds 1-7.

Table $1{ }^{1} \mathrm{H}$ and ${ }^{13} \mathrm{C}$ NMR spectral data of compounds 1 and $2^{\mathrm{a}}$

\begin{tabular}{|c|c|c|c|c|}
\hline \multirow[b]{2}{*}{ No. } & \multicolumn{2}{|r|}{1} & \multicolumn{2}{|r|}{2} \\
\hline & $\delta_{C}$ & $\delta_{H}(J$ in $\mathrm{Hz})$ & $\delta_{C}$ & $\delta_{H}(\mathrm{~J}$ in $\mathrm{Hz})$ \\
\hline 1 & & & 126.5 & \\
\hline 2 & 159.8 & & 135.1 & $7.91(1 \mathrm{H}$, br. s) \\
\hline 3 & 151.2 & & 123.3 & \\
\hline 4 & 117.4 & & 132.2 & $7.89(1 \mathrm{H}$, br. $\mathrm{d}, J=8.3)$ \\
\hline 5 & 125.8 & $8.84(1 \mathrm{H}, \mathrm{br} \mathrm{s})^{\mathrm{b}}$ & 116.8 & $6.95(1 \mathrm{H}, \mathrm{d}, J=8.3)$ \\
\hline 6 & 126.6 & & 160.6 & \\
\hline 7 & 128.2 & $8.06(1 \mathrm{H}, \mathrm{dd}, J=1.4,8.9)$ & 170.5 & \\
\hline 8 & 112.0 & $7.80(1 \mathrm{H}, \mathrm{dd}, J=8.9)$ & & \\
\hline 9 & 155.1 & & & \\
\hline 10 & 127.1 & & & \\
\hline 11 & 165.7 & & & \\
\hline 12 & 167.1 & & & \\
\hline
\end{tabular}

aNMR spectra were recorded at $600 \mathrm{MHz}$ for ${ }^{1} \mathrm{H}$ and $150 \mathrm{MHz}$ for ${ }^{13} \mathrm{C}$ in DMSO- $d_{6}$ for 1 and $\mathrm{CD}_{3} \mathrm{OD}$ for 2 .

bProton resonance integral, multiplicity and coupling constants in parenthesis.

quaternary carbons at $\delta 155.1$ and 151.2, three $\mathrm{sp}^{2}$ methine carbons at $\delta$ 128.2, 125.8 and 112.0; and three $\mathrm{sp}^{2}$ quaternary carbons at $\delta$ 127.1, 126.6 and 117.4 were evident (Table 1). The structure of 1 was determined by the HMBC spectrum, which showed the long-range correlations from H-5 to C-4, C-7, C-9 and C-12; from H-7 to C-5, C-9 and C-12; and H-8 to C-6, C-9 and C-10, as shown in Figure 2. The $\alpha$, $\beta$-unsaturated ester carbonyl carbon at $\delta 159.8$ was connected to an oxygenated $\mathrm{sp}^{2}$ quaternary carbon $(\mathrm{C}-3)$ at $\delta 151.2$, and the remaining carboxylic acid was connected to $\mathrm{C}-4$. If the hydroxyl group and the carboxylic acid were connected to $\mathrm{C}-4$ and $\mathrm{C}-3$, respectively, the $\mathrm{C}-3$ and C-4 chemical shifts would be shifted up-field and down-field, respectively. Consequently, the structure of 1 was 3-hydroxy-2-oxo- $2 \mathrm{H}$ chromene-4,6-dicarboxylic acid. This compound was isolated for the first time in this study.

Compound 2 was obtained as a yellow powder, and its Electrospray ionization mass in positive mode provided a quasi-molecular ion peak at $m / z 275[\mathrm{M}+\mathrm{H}]^{+}$, suggesting a molecular weight of 274 . The molecular formula of 2 was $\mathrm{C}_{14} \mathrm{H}_{10} \mathrm{O}_{6}$ based on the high-resolution electron ionization mass $\left(\mathrm{m} / z 274.0479[\mathrm{M}]^{+}\right.$, calcd 274.0478) and the ${ }^{1} \mathrm{H}$ and ${ }^{13} \mathrm{C}$ NMR data. The UV spectrum in methanol showed maximum absorption at 216 and $239 \mathrm{~nm}$. The ${ }^{1} \mathrm{H}$ NMR spectrum showed signals due to a 1,2,4-trisubstituted benzene at $\delta 7.91$<smiles>O=C(O)c1c(O)c(=O)oc2cccc(C(F)(F)C(=O)O)c12</smiles>

1

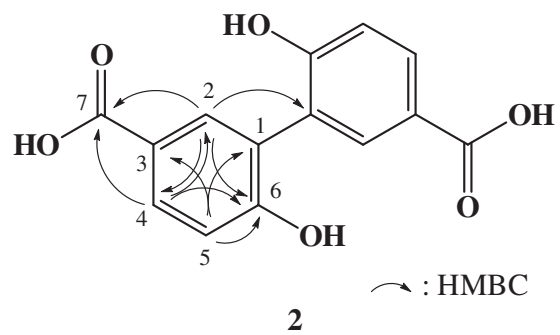

Figure $2 \mathrm{HMBC}$ of compounds $\mathbf{1}$ and 2.

Table 2 Antioxidant activities of compounds 1-7

\begin{tabular}{|c|c|c|}
\hline \multirow[b]{2}{*}{ Compounds } & \multicolumn{2}{|c|}{$I C_{50}(\mu M)^{a}$} \\
\hline & $A B T S^{b}$ & $D P P H^{C}$ \\
\hline 1 & $>400.0$ & $>400.0$ \\
\hline 2 & $48.1 \pm 3.4$ & $389.1 \pm 4.0$ \\
\hline 3 & $39.2 \pm 0.4$ & $258.6 \pm 3.5$ \\
\hline 4 & $68.6 \pm 4.3$ & $>400.0$ \\
\hline 5 & $13.0 \pm 1.3$ & $56.9 \pm 2.0$ \\
\hline 6 & $>400.0$ & $>400.0$ \\
\hline 7 & $44.7 \pm 1.5$ & $206.2 \pm 3.5$ \\
\hline $\mathrm{BHA}^{\mathrm{d}}$ & $23.0 \pm 2.3$ & $154.4 \pm 3.8$ \\
\hline Trolox & $38.8 \pm 1.2$ & $113.2 \pm 3.3$ \\
\hline
\end{tabular}

${ }^{a} C_{50}$ values represent the concentration that caused a $50 \%$ loss of antioxidant activity. b2,2'-Azinobis-(3-ethylbenzothiazoline-6-sulfonic acid).

${ }^{c} \alpha, \alpha$-Diphenyl- $\beta$-picrylhydrazyl.

dButylated hydroxyanisole. 


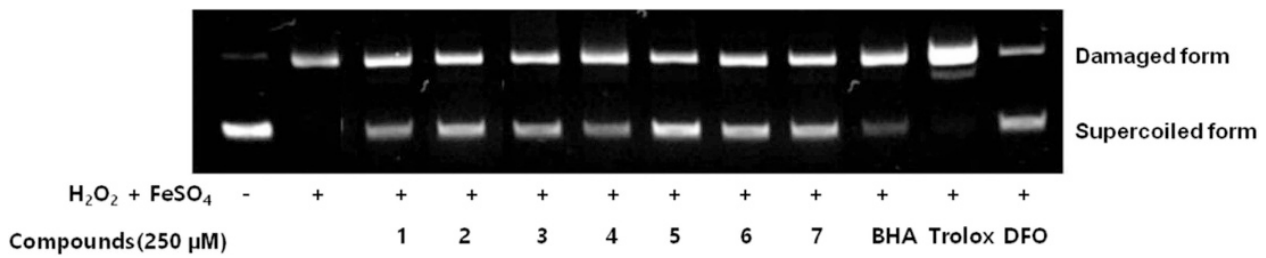

Figure 3 Protective effects of compounds 1-7 against plasmid DNA breakage due to the Fenton reaction between ferrous and hydrogen peroxide. Butylated hydroxyanisole (BHA), Trolox and deferoxamine (DFO) were used as controls.

(1H, br. s), 7.89 (1H, br. d, $J=8.3 \mathrm{~Hz})$, and $6.95(1 \mathrm{H}, \mathrm{d}, J=8.3 \mathrm{~Hz})$. Seven carbon peaks in the ${ }^{13} \mathrm{C}$ NMR spectrum, comprising one carbonyl carbon at $\delta 170.5$, one oxygenated $\mathrm{sp}^{2}$ quaternary carbon at $\delta$ 160.6, three $\mathrm{sp}^{2}$ methine carbons at $\delta 135.1,132.2$, and 116.8; and two $\mathrm{sp}^{2}$ quaternary carbons at $\delta 126.5$ and 123.3 were observed. Seven carbon peaks in the ${ }^{13} \mathrm{C}$ NMR spectrum suggested that 2 was a symmetrical dimer. The structure of $\mathbf{2}$ was determined by the HMBC spectrum. The long-range correlations from $\mathrm{H}-2$ and $\mathrm{H}-4$ to the carbonyl carbon at $\delta 170.5(\mathrm{C}-7)$ revealed that the carbonyl carbon was connected to C-3. Finally the methine proton at $\delta 7.91$ ( $\mathrm{H}-2)$ showed the long-range correlation to the quaternary carbon at $\delta 126.5(\mathrm{C}-1)$, establishing the structure of 2 as 6,6'-dihydroxy(1,1'-biphenyl)-3,3'-dicarboxylic acid. Although compound 2 was synthesized previously during synthesis of a biphenyl compound, ${ }^{15}$ it was isolated and reported for the first time from a natural source.

Compounds 3-7 were identified as 4-(3,4-dihydroxyphenyl)but3-en-2-one (3), ${ }^{16}$ 4-hydroxy-3,5-dimethoxybenzoic acid (4), ${ }^{17} 3,4$ dihydroxybenzaldehyde $(5),{ }^{16}$ 4-hydroxybenzene-1,3-dioic acid $(6)^{18}$ and 3,4-dihydroxybenzoic acid (7), ${ }^{19}$ respectively, based on their physicochemical properties and NMR spectral data, which were in good agreement with those published previously.

Free radical scavenging activities were evaluated by measuring scavenging effects against the 2,2'-azinobis-(3-ethylbenzothiazoline-6sulfonic acid) radical cation and $\alpha, \alpha$-diphenyl- $\beta$-picrylhydrazyl radical. These assays provide information on the reactivity of test compounds with a stable free radical. The isolated compounds exhibited radical scavenging activities in a dose-dependent manner. Compound 5 showed higher 2,2'-azinobis-(3-ethylbenzothiazoline-6-sulfonic acid) radical scavenging activity than that of the synthetic antioxidants butylated hydroxyanisole and Trolox, and compounds 2, 3 and 7 had comparable activities to that of the antioxidant Trolox (Table 2). A hydroxy radical bioassay has been developed using the Fenton reaction-induced DNA single-strand breakage method. ${ }^{20}$ Fenton chemistry produces strong oxidant hydroxyl radical with a reaction between iron and hydrogen peroxide, causing breaks in the DNA deoxyribose-phosphate backbone. This assay quantifies single-strand DNA breaks generated by a single nick in supercoiled DNA. Compound 5 significantly inhibited the Fenton reaction at $250 \mu \mathrm{M}$, resulting in protection against DNA damage, whereas the other compounds exhibited moderate activity at the same concentration (Figure 3).

\section{CONFLICT OF INTEREST}

The authors declare no conflict of interest.

\section{ACKNOWLEDGEMENTS}

This study was supported by a grant from the Korea Forest Service and by Basic Science Research Program through the National Research Foundation of Korea (NRF) funded by the Ministry of Education, Science and Technology (2013062358), Republic of Korea.

1 Imazeki, R. \& Hongo, T. Colored Illustrations of Mushrooms of Japan 492 (Hoikusha, Osaka, 1989).

2 Ma, L., Chen, H., Dong, P. \& Lu, X. Anti-inflammatory and anticancer activities of extracts and compounds from the mushroom Inonotus obliquus. Food Chem. 139, 503-508 (2013).

3 Zheng, W. et al. Chemical diversity of biologically active metabolites in the sclerotia of Inonotus obliquus and submerged culture strategies for up-regulating their production. Appl. Microbiol. Biotechnol. 87, 1237-1254 (2010)

4 Lee, I. K., Kim, Y. S., Jang, Y. W., Jung, J. Y. \& Yun, B. S. New antioxidant polyphenols from the medicinal mushroom Inonotus obliquus. Bioorg. Med. Chem. Lett. 17, 6678-6681 (2007).

5 Babitskaia, V. G., Shcherba, V. V. \& Ikonnikova, N. V. Melanin complex of the fungus Inonotus obliquus. Prikl. Biokhim. Mikrobiol. 36, 439-444 (2000).

6 Liu, C. et al. Chemical constituents from Inonotus obliquus and their biological activities. J. Nat. Prod. 77, 35-41 (2014)

7 Kahlos, K., Kangas, L. \& Hiltunen, R. Antitumor activity of triterpenes in Inonotus obliquus. Planta Med. 52, 554 (1986).

8 Shibnev, V. A. et al. Antiviral activity of Inonotus obliquus fungus extract towards infection caused by hepatitis C virus in cell cultures. Bull. Exp. Biol. Med. 151, 612-614 (2011)

9 Li, Y. F. \& Liu, Z. Q. Dendritic antioxidants with pyrazole as the core: ability to scavenge radicals and to protect DNA. Free Radic. Biol. Med. 52, 103-108 (2012).

10 Yoshida, Y., Saito, Y., Jones, L. S. \& Shigeri, Y. Chemical reactivities and physical effects in comparison between tocopherols and tocotrienols: physiological significance and prospects as antioxidants. J. Biosci. Bioeng. 104, 439-445 (2007).

11 Pryor, W. A. Vitamin E and heart disease: basic science to clinical intervention trials. Free Radic. Biol. Med. 28, 141-164 (2000).

12 Chandra, J., Samali, A. \& Orrenius, S. Triggering and modulation of apoptosis by oxidative stress. Free Radic. Biol. Med. 29, 323-333 (2000).

13 Hancork, J. T., Desikan, R. \& Neill, S. J. Role of reactive oxygen species in cell signalling pathways. Biochem. Soc. Trans. 29, 345-350 (2001).

14 Wells, P. G. et al. Oxidative stress in developmental origins of disease: teratogenesis, neurodevelopmental deficits, and cancer. Toxicol. Sci. 108, 4-18 (2009)

15 Maeda, K. et al. Preparation of biphenyl compounds as antibacterial agents. Japan Patent.172 2014108928. (2014)

16 Zan, L. F. et al. Antioxidant hispidin derivatives from medicinal mushroom Inonotus hispidus. Chem. Pharm. Bull. 59, 770-772 (2011)

17 Nakajima, Y., Sato, Y. \& Konishi, T. Antioxidant small phenolic ingredients in Inonotus obliquus (persoon) Pilat (Chaga). Chem. Pharm. Bull. 55, 1222-1226 (2007).

18 Srivastava, A., Harish, R. \& Shivanandappa, T. Novel antioxidant compounds from the aqueous extract of the roots of Decalepis hamiltonii (Wight and Arn.) and their inhibitory effect on low-density lipoprotein oxidation. J. Agric. Food Chem. 54, 790-795 (2006).

19 Flamini, G., Antognoli, E. \& Morelli, I. Two flavonoids and other compounds from the aerial parts of Centaurea bracteata from Italy. Phytochemistry 57, 559-564 (2001).

20 Lee, I. K., Jung, J. Y., Kim, Y. S., Rhee, M. H. \& Yun, B. S. p-Terphenyls from the fruiting bodies of Paxillus curtisii and their antioxidant properties. Bioorg. Med. Chem. 17, 4674-4680 (2009). 